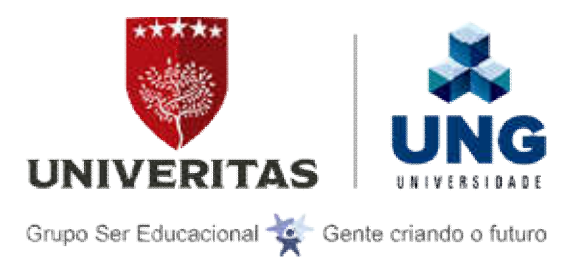

UNIVERSIDADE GUARULHOS

SABRINA PEREIRA RIBEIRO

\title{
PREVALÊNCIA DE MICRORGANISMOS INDICADORES FECAIS E POTENCIALMENTE PATOGÊNOS EM AREIA DA RECREAÇÃO INFANTIL EM PARQUE MUNICIPAL DE GUARULHOS-SP
}


PREVALÊNCIA DE MICRORGANISMOS INDICADORES FECAIS E POTENCIALMENTE PATOGÊNOS EM AREIA DA RECREAÇÃO INFANTIL EM PARQUE MUNICIPAL DE GUARULHOS - SP

Trabalho de Conclusão de Curso apresentado ao curso de Biomedicina da Universidade Guarulhos, para obtenção do título de bacharel em Biomedicina

Orientadora: Profa. Dr. Priscila Luiza Mello.

\section{Guarulhos}

2020 
Tudo posso Naquele que me fortalece. Bíblia livro de Filipenses Capítulo4 versículo 13 


\section{AGRADECIMENTOS}

A Deus por me abençoar com sabedoria, saúde e força.

Aos meus pais, que me ensinaram que o conhecimento é um recurso valioso que possibilita mudanças incriveis.

Ao meu marido, meu incentivador.

Aos meus filhos Beatriz, Giovanna e Gustavo que inspiram minhas conquistas.

Ao meu irmão e cunhada que me apoiaram desde que me matriculei neste curso.

Aos professores do curso de Biomedicina desta universidade, em especial Rulian Ricardo Faria e Marta Souza

Aos colegas de sala, pelas experiências somadas no dia a dia, em especial agradeço a Caroline Rangel e Laís Ribeiro pelos trabalhos em grupos sempre realizados com muita responsabilidade.

A Aline Brennecke que passou de colega de faculdade a uma amiga importante na vida, companheira de estudos, e parceira neste trabalho de conclusão de curso.

A Carolyn Carrecelli responsável pelo laboratório de microbiologia de alimentos desta instituição, pela sua paciência e sua disposição na preparação dos caldos para o trabalho prático deste estudo.

E a minha orientadora Priscila Luiza Mello que me ensinou sobre Biologia Molecular, Biotecnologia e Embriologia Clínica e o fez de uma maneira tão incrível, que eu a escolhi para me orientar, pois uma professora tão jovem e ao mesmo tempo tão experiente na área da pesquisa, ela nunca se enalteceu, e podia fazê-lo, pois sua bagagem de conhecimento é enorme assim como sua simplicidade e sua pedagogia. Ela despertou em mim a sede pela pesquisa, me incentivou ao trabalho prático e fez tudo com muito amor, obrigada ProfDra Priscila. 
Introdução: Parques públicos são locais de diversão integrados à sociedade atendendo a população e geralmente são considerados locais seguros. A maior preocupação é no uso correto dos equipamentos disponíveis, para evitar acidentes, e de fato o perigo é menos aparente. Objetivo: Este estudo se concentra no chão do parque infantil como fonte de contaminação microbiana. Método: As Amostras foram processadas no laboratório de microbiologia da Universidade de Guarulhos, e sua análise realizada através de tubos múltiplos e os resultados obtidos foram comparados com a tabela NMP.Resultados: O crescimento de microorganismos na placa de PCA foi incontável e se fez necessárias diluições $10^{2}$ e $10^{3}$. Conclusão: Se faz necessários parâmetros e leis de controle da qualidade de higiene da areia recreativa que sejam eficazes para controle.

Descritores: coliformes, crianças, tubos múltiplos, contaminação, areia. 


\begin{abstract}
Introduction: Public parks are places of leisure integrated to society serving the population and are generally considered safe places. The biggest concern is in the correct use of the available equipment, to avoid accidents, and in fact the danger is less apparent. Objective: This study focuses on the playground floor as a source of microbial contamination. Method: The samples were processed in the microbiology laboratory at the University of Guarulhos, and their analysis was carried out using multiple tubes and the results obtained were compared with the NMP table. Results: The growth of microorganisms on the PCA plate was countless and dilutions $10^{2}$ and $10^{3}$ were necessary. Conclusion: It is part of the parameters and laws of quality control of recreational sand hygiene that are effective for control.
\end{abstract}

Keywords: coliforms, children, multiple tubes, contamination, sand. 


\section{RESUMÉN}

Introducción: Los parques públicos son lugares de entretenimiento integrados alasociedad al servicio de lapoblación y generalmente se consideran lugares seguros. La mayorpreocupación está enel uso correctodel equipo disponible, para evitar accidentes, y de hechoelpeligro es menos aparente. Objetivo: Este estudio se centra enelsuelodelpatio de recreo como fuente de contaminación microbiana. Método: Lasmuestras se procesaronenellaboratorio de microbiología de laUniversidad de Guarulhos, y suanálisis se realizó mediante múltiples tubos y los resultados obtenidos se compararonconla tabla NMP. Resultados: El crecimiento de microorganismosenla placa PCA fueincontable y fueronnecesariasdiluciones $10^{2}$ y $10^{3}$. Conclusión: Es necesario contar conparámetros y leyes para elcontrol de calidad de la higiene de la arena recreativa que seanefectivos para sucontrol.

Palabras clave: coliformes, niños, tubos múltiples, contaminación, arena. 
PREVALÊNCIA DE MICRORGANISMOS INDICADORES FECAIS E POTENCIALMENTE PATOGÊNICOS EM AREIA E RECREAÇÃO INFANTIL EM PARQUE MUNICIPAL DE GUARULHOS-SP

PREVALENCE OF FECAL AND POTENTIALLY PATHOGEN INDICATOR MICRO-ORGANISMS IN THE SAND OF CHILDREN'S RECREATION IN A MUNICIPAL PARK IN GUARULHOS-SP

\title{
PREVALENCIA DE MICROORGANISMOS INDICADORES FECALES Y POTENCIALMENTE PA- TÓGENOS EN LA ARENA DE RECREACIÓN INFANTIL DE UN PARQUE MUNICIPAL DE GUA- RULHOS-SP
}

\author{
Sabrina Pereira Ribeiro ${ }^{1}$; Priscila Luiza Mello²
}

\begin{abstract}
${ }^{1}$ Discente do curso de Biomedicina, Universidade Univeritas - UNG,Guarulhos, SP, Brasil ${ }^{2}$ Bióloga, doutora em Biologia Geral e Aplicada pela Universidade Estadual Paulista Júlio de Mesquita - UNESP - Docente do curso de Biomedicina na Universidade Univeritas - UNG - Guarulhos, SP, Brasil
\end{abstract}

Introdução

Parques em todo o mundo oferecem oportunidades recreativas para centenas de pessoas. No entanto, evidências crescentes sugerem que a areia presente nesses ambientes pode abrigar altas concentrações de microrganismos prejudiciais à saúde humana ${ }^{1}$. Conforme a Companhia Estadual de Tecnologia e Saneamento Básico-CETESB, as pessoas mais suscetíveis à exposição a bactérias, vírus e protozoários são as crianças, idosos e com baixa resistência imunológica².

O grupo dos coliformes constitui o indicador de contaminação fecal mais frequentemente utilizado, sendo empregado, há mais de cem anos, como parâmetro bacteriano, na definição de padrões para a caracterização e avaliação da qualidade de águas e alimentos ${ }^{3}$. Os coliformes totais são um grupo de bactérias que contém bacilos gram-negativos, aeróbios ou anaeróbios facultativos e que fermentam a lactose com produção de ácidos, aldeídos e gás a $35^{\circ} \mathrm{C}$ em $24-48$ horas. Coliformes fecais ou coliformes termotolerantes são bactérias capazes de desenvolver e/ou fermentar a lactose com produção de gás a $44^{\circ} \mathrm{C}$ em 24 horas ${ }^{4}$.

Dentro do grupo dos coliformes termotolerantes, a principal bactéria é a $E$. Coli, pois seu habitat é o trato intestinal, sendo abundante em fezes de humanos e animais de sangue quente. Dos coliformes presentes nas fezes, 95\% são representados por essa bactéria, portanto é uma indicadora de contaminação de origem fecal ${ }^{5}$.

A designação para coliformes totais inclui as bactérias em forma de bastonetes Gram Negativos, não esporogênicos, aeróbios ou anaeróbios facultativos, capazes de fermentar a lactose com produção de gás, em 24 a 48 horas a $35^{\circ} \mathrm{C}$. (06) O grupo inclui: Escherichia spp., Citrobacterspp.,Enterobacterssp., Klebsiellaspp, Pseudomonas spp. O Ministério da Saúde, pela resolução $\mathrm{n}^{\circ}$ 12, de 2 de janeiro de 2001, da Agência Nacional de Vigilância Sanitária adotou a denominação de coliformes fecais para coliformes a $45^{\circ} \mathrm{C}$, considerando os padrões "coliformes de origem fecal" e "coliformes termotolerantes" 6 . 
A matriz areia é reconhecida pela Organização Mundial da Saúde (OMS) como um vetor de infecção ${ }^{7}$. Tomados em conjunto, esses estudos contextualizam um problema potencial de saúde pública e identificam questões de pesquisa que devem ser abordadas. Embora não exista uma legislação especifica no Brasil que determine um limite de contaminação de areias, a resolução $n^{\circ} 274$ CONAMA (2000) em seu Art. $8^{\circ}$ recomenda aos órgãos ambientais a avaliação das condições parasitológicas e microbiológicas da areia, para futuras padronizações. O projeto de lei original $n^{\circ} 2.297$, de 2003, retomado em 2009, dispõe sobre a obrigatoriedade de tratamento e assepsia de areia, para futuras padronizações ${ }^{8}$.

O projeto de lei original $n^{\circ} 2.297$, de 2003 , retomado em 2009, dispõe sobre a obrigatoriedade tratamento e assepsia de areia contida em tanques de lazer e recreação, existentes em áreas públicas e privadas ${ }^{9}$.Atualmente são utilizados valores propostos por pesquisadores portugueses ${ }^{10}$. Outro padrão que se tem usado para o controle de coliformes em areia é o mesmo utilizado para pesquisa de coliformes em águas e alimentos, a Técnica do Número Mais Provável (NMP) por mL, uma técnica clássica, rápida e de baixo custo. O NMP analisa o crescimento celular microbiano pela leitura da turvação do meio e determinação de produtos metabólicos no meio, como gases, ácidos e alcoóis ${ }^{11}$.

Como não há regulamentação dispondo sobre a investigação da qualidade microbiológica das areias de parques públicos, e tendo em vista que essas podem oferecer risco à saúde, o objetivo deste estudo foi avaliar a qualidade microbiológica da areia de um parque público na cidade de Guarulhos - SP através da técnica do número mais provável de coliformes totais e termotolerantes e contagem de bactérias heterótrofas mesófilas ${ }^{12}$.

\section{MÉTODO}

\section{Local de estudo e período da coleta}

A cidade de Guarulhos-SP possui 15 parques públicos e destes, apenas 9 com área de recreação infantil. A escolha do local se deu pela diversidade de pessoas que frequentam epela presença de pontos de vendas de alimentos prontos para consumo, o que atrai animais e aves pelos restos de alimentos. O Parque Municipal se encontra entre o centro e uma comunidade. A coleta ocorreu no dia 13 de setembro de 2020 , às $16 \mathrm{~h}$, a temperatura neste dia estava em torno de $34^{\circ} \mathrm{C}$, foram utilizados três frascos de $15 \mathrm{ml}$ cada, a coleta foi feita próximo ao brinquedo escorregador, pois havia muitas crianças neste local.

\section{Coleta do Material}

Foram utilizados três fracos de $15 \mathrm{ml}$, previamente esterilizados a $121^{\circ} \mathrm{em}$ autoclave por 15 minutos, e abertos apenas no momento da coleta, diretamente na areia a ser analisada. As amostras foram acondicionadas em caixa de isopor com gelo reciclável e posteriormente levado para o laboratório de Microbiologia da Universidade de Guarulhos-SP. 


\section{Preparo das amostras}

Todo material coletado (aproximadamente $45 \mathrm{~g}$ ) foicolocado em uma placa devidamente esterilizada. Em seguida, pesamos $25 \mathrm{~g}$ do material a ser analisado. As alíquotas de $25 \mathrm{~g}$ foram adicionadas a $225 \mathrm{ml}$ de água peptonada $0,1 \%$ esterilizada ehomogeneizou-se com movimentos circulares manualmente por 20 minutos, obtendo-se a diluição $10^{-1}$. Para as demais diluições, $10^{-2}$ e $10^{-3}$, aliquotas de $1 \mathrm{ml}$ foram adicionadas em $9 \mathrm{~mL}$ de água peptonada $0,1 \%$ esterilizada.

Procedimento Microbiológico:Número mais provável (NMP) de coliformes totais e coliformes $\mathrm{a}^{\circ}{ }^{\circ} \mathrm{C}$

O Número Mais Provável (NMP) de coliformes totais e coliformes fecais foi determinado através da técnica dos Tubos Múltiplos. A análise compreende duas fases distintas: a fase do teste presuntivo e a fase do teste confirmativo ${ }^{13}$. No teste presuntivo foram utilizadas três séries de tubosde ensaio contendo tubos de Durham e Caldo Lactosado.

Foram feitas 3 séries de tubos contendo Caldo LaurilTriptose(Acumedia), com inóculos de 1 $\mathrm{ml}$ das diluições $10^{-1}, 10^{-2}$ e $10^{-3}$. As 3 séries de tubos foram incubadas a $37^{\circ} \mathrm{C}$ por $24-48$ horas. Após o período de incubação, os tubos que apresentaram produção de gás devido à fermentação da lactose do meio, evidenciada pela formação de bolhas no tubo de Durham, foram considerados positivos no teste presuntivo. Para confirmação de coliformes totais (Teste Confirmatório e Diferencial) é efetuado o repique, retirados $1,0 \mathrm{ml}$ de cada tubo que produziu gás o caldo LaurilTriptose (Acumedia) e semeando nos três tubos contendo $9 \mathrm{~mL}$ de Caldo Verde Brilhante - CLBVB (Acumedia) e outros 1,0 mL em 03 tubos com $9 \mathrm{~mL}$ de Caldo E.C (Acumedia) com tubos de Durham invertidos ${ }^{14}$.

Portanto, seguimos a partir das diluições $10^{-1}, 10^{-2}$ e $10^{-3}$ da amostra. Com o auxílio de alça de níquel cromo foram retiradas alíquotas dos tubos positivos e transferidas para tubos contendo Caldo Verde Brilhante Lactose Bile (CVBLB) e para tubos contendo Caldo E.C, para a confirmação de coliformes totais e de coliformes fecais $\left(45^{\circ} \mathrm{C}\right)$, respectivamente. Os tubos contendo CVBLB foram incubados a $35^{\circ} \mathrm{C}$ por $24-48$ horas. Os tubos de Durham com produção de gás foram considerados positivos para coliformes totais, podendo ser de origem fecal ou não. Os tubos contendo EC foram utilizados para a detecção de coliformes de origem fecal. A temperatura e o período de incubação ( $45^{\circ} \mathrm{C}$ por 24 horas) impedem que outros microrganismos fermentem a lactose, desse modo, se houver produção de gás fica clara a presença de coliformes fecais ${ }^{15}$.

\section{Contagem das Unidades Formadoras de Colônias}

Para a avaliação da qualidade sanitária da areia coletada, foram quantificadas as bactérias heterótrofasmesófilas, segundo o crescimento das colônias no ágar Plate Count Agar (PCA).

Pela técnica de semeadura em superfície, alíquotas de $0,1 \mathrm{~mL}$ das diluições $10^{-1}, 10^{-2}$ e $10^{-}$

${ }^{3}$ foram transferidas para placas de petri contendo o meio de cultura e, em seguida, espalhadas cuidadosamente com alça de drigalski, por toda a superfície até que fossem totalmente absorvidas. A seguir, incubadas a uma temperatura de $35^{\circ} \mathrm{C}$ por 24 a 48 horas ${ }^{16}$. 


\section{RESULTADOS}

Após a análise microbiológica, foi possível detectar altíssimos níveis de bactérias, indicadoras decontaminação. O crescimento de bactérias heterotróficas na placa com PCA (Plate CountAgar) em sua primeira diluição $10^{-1}$ foi incontável e se fez necessário proceder com as diluições $10^{-2}$ e $10^{-3}$ que se mantiveram incontáveis. (vide figura 1).Determinado pela seguinte fórmula:

\section{$10^{3}-100 \mathrm{UFC} / \mathrm{cm}^{2}(6.500 \times 1.000)=6.500 .0006,5 \times 10 \mathrm{UFC} / \mathrm{MI}$}
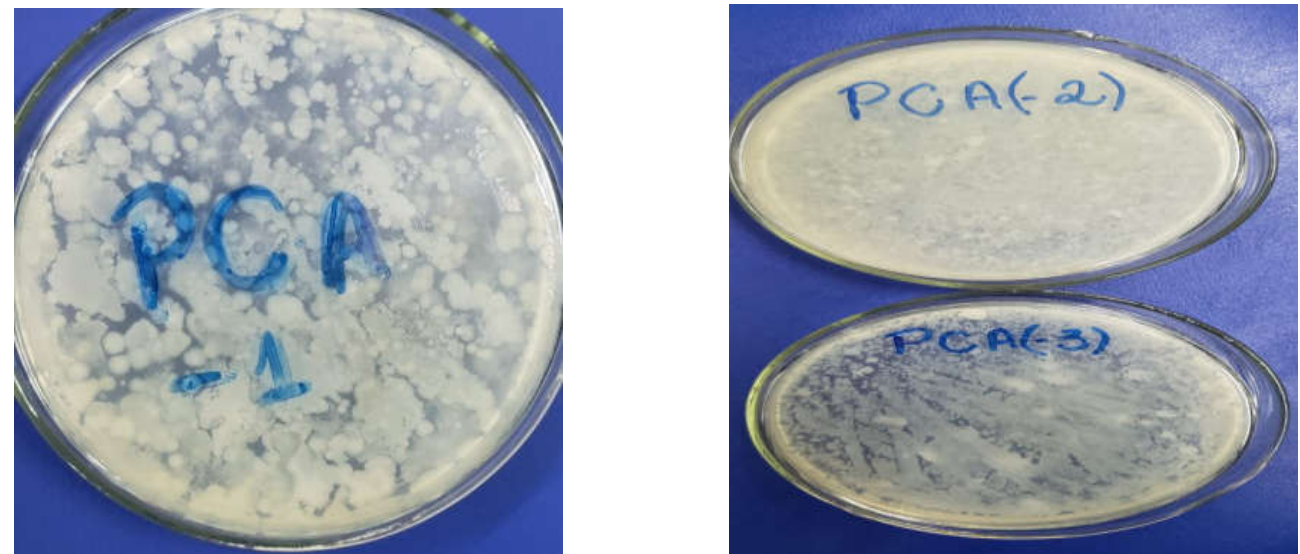

Figura 1 - Resultado bactérias heterotróficas meio de cultura PCA (Plate Count Agar). Diluições 101 $-10^{2}-10^{3}$

Os resultados que confirmaram a contaminação por Coliformes Totais e Fecais foram obtidos por meio do número de tubos utilizando caldo VB (caldo verde brilhante bile) para a contagem de coliformes totais e caldos EC(ágar vrbmug) para a contagem de coliformes termotolerantespositivos de cada diluição (Vide figura 2).

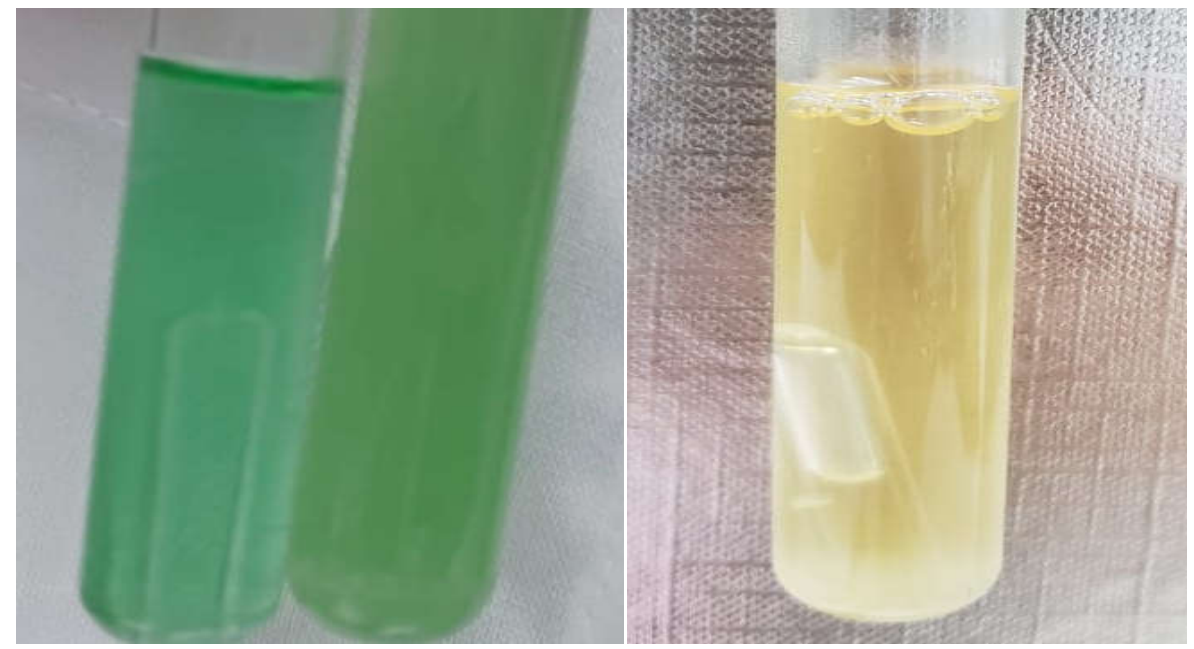

Figura 2: Caldo Verde Brilhante Bile - Coliformes Totais Positivo e Caldo E.C. Coliformes Termotolerantes, ambos com produção de gás. 
E são expressos como número mais provável (NMP) -(Vide tabela 1) - Fonte: Bacteriological

Tabela 1. Analytical Manual Food And Drug Administration 1984 apud $^{17}$.

\begin{tabular}{|c|c|c|}
\hline Combinações Tubos & $\mathrm{NMP} / \mathrm{mL}$ & Min./ Max \\
\hline $\begin{array}{lll}3 & 3 & 3\end{array}$ & $>2400$ & $>1500>4800$ \\
\hline
\end{tabular}

Tabela 2. Presença de Coliformes Totais, Coliformes Fecais e UFC/mL - Resultado da Análise

\begin{tabular}{|c|c|c|c|}
\hline Amostra & Coliformes Totais & Coliformes Fecais & $\mathrm{UFC} / \mathrm{mL}$ \\
\hline Areia & Positivo & Positivo Incontáveis & \\
\hline
\end{tabular}

\section{DISCUSSÃO}

Devido à escassez de estudos enormatizações sobre a análise de areiasem praças derecreação e à inexistência, noBrasil, de parâmetros e índices estabelecidospelos órgãos ambientais para o controlemicrobiológico de areias, optou-se porparâmetros utilizados pela Técnica do NúmeroMais Provável, utilizado no controle decontaminação da água e de alimentos.

Esta técnica é vantajosa, pois é possível analisar amostras claras e turvas. O processamento da amostra pode ser feito a qualquer hora do dia. O número desses microrganismos é apontado pelo Número Mais Provável (NMP) que indica o grau de contaminação e, portanto, existem microrganismos patogênicos. Tabela do NMP/ $100 \mathrm{~mL}$, conforme combinações de tubos, com o valor máximo e valor mínimo em um intervalo de confiança de $95 \%$ de probabilidade ${ }^{18}$.

Nos poucos estudos sobre este assunto, Andraus (2006) verificou Aspectos microbiológicos da areia das praias de Matinhos, Caiobá e Guaratuba (PR), utilizando os parâmetros microbiológicos determinados na Resolução Conama 20/86 (Índice máximo de coliformes totais 5000 NMP / $100 \mathrm{~mL}$ ) e resolução Conama 274/00 (Índice máximo de flora coliforme Resistente ao calor 1000 NMP / 100 $\mathrm{mL}$ ) para a água, porque não há parâmetros específicos para areia $^{19}$.

Os coliformes são os microrganismos mais utilizados para indicar contaminação fecal de humanos ou animais em água, o que a torna imprópria para o consumo humano.Otermo "coliformes totais" inclui amplo rol de bactérias ambientais e de origem fecal capazes de sobreviver no meio aquático, fermentar a lactose e produzir ácido ou aldeído em 24 horas à temperatura de 35 a $37^{\circ} \mathrm{C}$. Estas apresentam diversascaracterísticasque explicam o extensivo emprego como indicadores microbiológicos de qualidade de água. A primeira refere-se à elevada quantidade eliminada diariamente por um indivíduo (de $1 / 3$ a $1 / 5$ do peso das fezes), culminando com concentrações nos esgotos domésticos de 106 a 108 organismos/mL. Assim, eleva-se a probabilidade da detecção dos coliformes nas amostras de água bruta e a possibilidade da presença depatogênicos a estes associados ${ }^{20}$.

Para bactérias heterotróficas, a norma estipula um valor máximo permitido de 500 Unidades Formadoras de Colônias (UFC) para cada100 mL de água, e de acordo com as análises, observouse umvalor bem superior. As bactérias heterotróficas estão presentes em todos os tipos de água, nos alimentos, no solo, na vegetação e no ar. Sua contagem podefornecer uma indicação geral sobre a qualidade microbiológica da água tratada, e quando realizada regularmente pode demonstrar altera- 
ções devido ao armazenamento (recrescimento, formação de biofilme), eficiência dos métodos de tratamento, integridade e limpeza dosistema de distribuição ${ }^{21}$.

\section{CONCLUSÃO}

O presente estudo conclui que os microrganismos encontrados nas areias analisadas expõem pessoas que frequentam os locais de recreação, possibilitando riscos de contrair doenças.

Se compararmos os resultados encontrados neste trabalho aos valores acima, podemos verificar que a areia do parque infantil do Município de Guarulhos (SP) excede os limites permitidos por estas resoluções. O desconhecimento do risco associado à falta de qualidade sanitária dos ambientes devido à inexistência de monitoramento periódico nestes locais torna algumas áreas de recreação propícias à transmissão de patógenos presentes nas diferentes matrizes ambientais, portanto constituem problemas de saúde pública. É importante ressaltar bons hábitos de higiene aoutilizarem parques de recreação para minimizar os riscos de contrair doenças.

Assim, faz-se necessário desenvolver junto às comunidades ações centradas em práticas educativas e preventivas, tais como, higiene pessoal, saneamento básico, e ainda legislação proibindo animais em parques e praças, sendo medidas profiláticas importantes que podem ser tomadas.

\section{REFERÊNCIAS}

1. Sabino R, Rodrigues R, Costa I, Carneiro C, Cunha M, Duarte A, et al. Routine screening of harmful microorganisms in beach sands: implications to public health. The Scieofthe total envir [periódico na Internet]. 2013 Nov [acesso em 2020 Nov 18]; 472(1062): [aproximadamente 17p.]. Disponivel em: https://doi.org/10.1016/j.scitotenv.2013.11.091

2. Companhia de Tecnologia de Saneamento Ambiental. Relatório da balneabilidade das praias paulistas. São Paulo, Documento Técnico; 1998.

3. HaglerNA,HaglerLCSM, Roitman I; Travassos LR; Azevedo JL, editores. Microbiologia sanitária. $2^{a}$ ed. São Paulo: Manole, 1998.

4. Bettega JMPR, Machado MR, Presibella M,Baniski G, Barbosa CA. Métodos analíticos no controle microbiológico da água para consumo humano. Ciêc e Agrote[Periódico na internet].2006 Out [acesso em 2020 Nov 18]; 30(5):[aproximadamente 5 p]. Disponivel em: https://www.scielo.br/pdf/cagro/v30n5/v30n5a19.pdf

5. Agência Nacional de Vigilância Sanitária. Ministério da Saúde. Resolução $n^{\circ} 518$. BRASIL; 2004

6. Geus MIAJ,Lima JAI. Análise de coliformes totais e fecais [Um Comparativo entre técnicas oficiais VRBA e Petrifilm EC aplicados em uma indústria de carnes]. Campos Gerais: Anais do II Encontro de Engenharia e Tecnologia de Campos Gerais; 2006. 
7. PereiraE, FigueiraC, Aguiar N, Vasconcelos R, Vasconcelos S,Calado G, et al. Microbiological and mycological beach sand quality in a volcanic environment: Madeira archipelago. Portugal Scieofthe Total Envnt.2013; 461(469):462-479.

8. ConselhoNacionaldoMeioAmbiente. Resolução $n^{\circ} 274$. Brasil: Publicada no DOU $n^{\circ} 18$; 2000;(70-71p.)

9. Mendes B, Nascimento MJ, Oliveira JS.Preliminary characterization and proposal microbiological quality standard of sand beaches. Water Science \& Technology. 1993;27(3-4):453-456

10. Portugal, 2009.

11. CETESB. Companhia Ambiental do Estado de São Paulo. Coliformes termotolerantes: Determinação em amostras ambientais pela técnica de tubos múltiplos com meio A1 - método de ensaio. São Paulo. Documento Técnico, 2007.

12. Ribas MMF, Cunha ME. Metodologia para avaliação de grupos fisiológicos de microrganismos em digestão anaeróbia [Dissertação]. Botucatu: Faculdade de Ciências Agronômicas. Mestrado em Energia na Agricultura.Ambiência Revista do Setor de Ciências Agrárias e Ambientais. 1990

13. Ribas MMF; Cunha ME. Método de NMP para avaliação de grupos fisiológ de microrg em digestão anaeróbia de água residuária de mandioca. 2009 Dez; (3)401:417-5.

14. Cardoso CL. Análise bacteriológica de água.Man aulas práticas.2008; 86:87.

15. SilvaMP,Cavalli DR, OliveiraTCRM.Avaliação do padrão coliformes a $45^{\circ} \mathrm{C}$ e comparação da eficiência das técnicas dos tubos múltiplos e Petrifilm EC na deteç̧ão de coliformes totais e Escherichia coli em alimentos. Ciência e Tec Alimentos. 2006; 26(352):359-2.

16. CENEPI, FUNASA, MINISTERIO DA SAÚDE. Monitorização das Doenças Diarreicas Agudas. Mato Grosso do Sul: Documento Técnico; 1999.

17. Silva MP.Bacteriological Analytical Manual Food And Drug Administration.1984 apud modificado. 2001.

18. Bernardo MSMV. Comparação dos métodos aplicados na detecção de bactéria de coliformes, Escherichia coli e Enterococcussp. em águas para fins recreativos. Faro: Faculdade de Ciências e TecnologiaUniv do Algarves. 2007[Acesso em 2020 Nov 17].[121].Disponivel em: https://sapientia.ualg.pt/bitstream/10400.1/631/1/Disserta\%C3\%A7\%C3\%A3o.pdf

19. Andraus $S$. Aspectos microbiológicos da qualidade sanitária das águas do mar e areias das praias de Matinhos, Caiobá e Guaratuba-PR.[Dissertação Mestrado]. 2006 [acesso em 2020 Nov 18]:[132].Disponivel em:https://www.arca.fiocruz.br/bitstream/icict/2434/1/ENSP_Disserta\%C3\%A7\%C3\%A3o_Re go_Jane_da_Costa_Valentim.pdf

20. LibânioM. Fundamentos de qualidade e tratamento de água. $3^{a}$ Edição (Editora Átomo). Campinas-SP, 2010.

21. WHO. World Health Organization. Guidelines for safe recreational water environments: coastal and fresh waters. Geneva: World HealthOrganization; 2003. (v.1) p253. 